\title{
Circulating immune complexes and disease activity in Crohn's disease ${ }^{1}$
}

\author{
R. FIASSE ${ }^{2}$, A. Z. LURHUMA, C. L. CAMBIASO, P. L. MASSON, AND \\ C. DIVE
}

From the Gastroenterology Unit and International Institute of Cellular and Molecular Pathology, Université Catholique de Louvain, Belgium

SUMMARY Circulating immune complexes were determined in 59 consecutive patients with Crohn's disease and 100 blood donors by a double method based on the inhibition of the agglutinating activity of $\mathrm{CIq}$ and/or rheumatoid factor on IgG-coated polystyrene particles. In patients, the incidence of positive immune complexes was $63 \%$ and $61 \%$ at first testing, $85 \%$ and $78 \%$ at subsequent determinations; there was a good correlation between the inhibition titres of CIq and those of rheumatoid factor $(\mathrm{P}<0.001)$. In blood donors, the incidence was $22 \%$ and $14 \%$ at low titre. The incidence of immune complexes was the lowest $(36 \%)$ in the group of resected patients without signs of relapse; repeat determinations showed absence of immune complexes three months postoperatively. In patients medically treated for primary disease or relapse, rheumatoid factor titre higher than $1 / 1$ was less frequent than in medically untreated patients with active disease $(P<0.01)$. A significantly higher concentration of serum alpha-1-antitrypsin and orosomucoid, and a significantly lower level of serum iron were found in patients with an IC titre exceeding $1 / 1$; longitudinal studies showed in most cases a concordance between the evolution of immune complex titres, inflammatory parameters and clinical status.

A high incidence of circulating immune complexes (IC) has been reported in regional enterocolitis. Mowbray et al. (1973), using the CIq agar gel precipitation method (Agnello et al., 1970), found an incidence of $28 \%$ in 32 patients and none in controls. Doe et al. (1973), with the same method, found a $57 \%$ incidence in 21 patients and $3 \%$ in controls. Jewell and McLennon (1973) showed that sera of 18 patients with Crohn's disease significantly inhibited the antibody-induced cytotoxicity mediated by lymphocytes, compared with sera of 20 control subjects; this inhibition, attributed to small immune complexes, seemed related to the severity of the disease but there was no statistical evaluation, because of the small numbers.

To evaluate the significance of this abnormal immunological phenomenon in Crohn's disease, we measured the immune complexes in relation to the activity of the disease. We also studied the influence

1Presented in part at the Forum de Recherches de la Société Nationale Française de Gastro-entérologie, Lausanne, December 1976.

${ }^{2}$ Address for reprints: R.F., Service de Gastro-entérologie, Cliniques Universitaires St-Luc, Av. Hippocrate, 10, B-1200 Bruxelles, Belgium. of medical and surgical treatment. Therefore, the levels of immune complexes were determined in a large series of patients and controls. For this purpose, we used a method based on the inhibition by IC of the agglutinating activity of $\mathrm{CIq}$ and/or rheumatoid factor (RF) on IgG-coated polystyrene particles. This method has the advantage of detecting and titrating IC with two different reagents.

Even if immune complexes do not play a pathogenic role in Crohn's disease, their determination, as will be shown in the present study, could be useful for monitoring the evolution of the disease. It is also the first step before analysing the antigen(s) involved in the immune complexes, which could help to identify the aetiological agent(s).

\section{Methods}

PATIENTS

Sera were collected over a period of 15 months from 59 consecutive patients with Crohn's disease. The mean age was 39 years (range 15-72 years) and the series comprised 39 males and 20 females. Medical treatment was with sulphasalazine; in severe cases, corticosteroids were also given. The severity of the 
disease was evaluated on clinical, radiological, and biological grounds, without knowledge of the results of the IC determinations. Surgical treatment was by ileocolic resection. The diagnosis of Crohn's disease was based on characteristic and radiological findings, and was confirmed by histology in $86 \%$ of cases.

The patients were classified into five groups, depending upon the stage of the disease and the treatment previously given at the time the first blood sample was taken. These were: group I, nine patients with untreated primary disease (three ileitis, four ileocolitis, one colitis, one duodenitis); group II, 10 patients with medically treated primary disease (six ileitis and four ileocolitis); group III, 11 resected patients without relapse and without medical treatment except one who received $1.5 \mathrm{~g}$ sulphasalazine daily; group IV, 13 patients with ileal recurrence not yet treated; group V, 16 patients with ileal recurrence, medically treated. Ileal recurrence was usually confined to a short segment of the preanastomotic loop. One patient of group IV and one patient of group V had also a short segment of colitis adjacent to the anastomosis, and one patient of group $\mathrm{V}$ had also extensive colitis.

There was no significant age difference between the different groups. The mean duration of medical treatment was three years in group II (range 0-3 years) and two years in group IV (range 0-5 years). Two patients, one of each from groups I and IV, had erythema nodosum. One hundred healthy blood donors constituted a control group.

\section{TECHNIQUES}

\section{Detection of circulating immune complexes}

All analyses were performed by the same investigator who wasignorant of the clinical data. The method was described in detail by Lurhuma et al. (1976). Most sera were tested within 24 hours; some were kept at $4^{\circ} \mathrm{C}$ for a few days before testing. The rheumatoid factor reagent was the excluded portion of a Sephadex G-200 chromatography of the euglobulins of a rheumatoid patient serum, which had a Latex agglutination titre of $1 / 320$. Human CIq was isolated from fresh serum by the technique of Yonemasu and Strand (1971). We used human IgGcoated polystyrene particles (Latex-RF-Reagenz) purchased from Behring Institute (Marburg, West Germany). A volume of $20 \mu 1$ of the sample was mixed on a dark plate with an equal volume of the RF or CIq solutions already described, and then with $20 \mu \mathrm{l}$ of the Latex suspension. The plate was inspected for three minutes, and agglutination was scored as either positive or negative. For optimal sensitivity, RF and CIq solutions were used at the lowest concentrations still causing distinct agglutination, and these concentrations were determined anew for each series of tests. Before testing the inhibiting properties, each sample was already checked for the possible presence of spontaneous agglutinating activity due to endogenous rheumatoid factor. The inhibiting or agglutinating activity of the samples was titrated by twofold serial dilutions.

\section{Inflammatory parameters}

Serum proteins (orosomucoid, alpha-1-antitrypsin, haptoglobin, C3-factor of complement, IgA, IgM, and IgG) were determined by nephelometric immunoassay (AIP system, Technicon Instruments Corp., Tarrytown, N.Y.). The results are given as percentage of normal, with reference to a pool of sera from 1000 blood donors. Serum iron and plasma fibrinogen were measured in the general clinical laboratory.

\section{Results \\ INCIDENCE AND TITRES OF IMMUNE COMPLEXES}

In 174 samples of serum from 59 patients, immune complexes reactive with CIq were detected in the first blood sample from 37 patients $(63 \%)$ and in subsequent blood samples from 50 patients $(85 \%)$. With the rheumatoid factor method, IC were found in the first sample from 36 patients $(61 \%)$ and in subsequent samples from 46 patients $(78 \%)$.

Table 1 gives the percentage of positive immune

Table 1 Incidence of circulating immune complexes

\begin{tabular}{|c|c|c|c|c|c|c|c|}
\hline \multirow[t]{2}{*}{ Group } & \multirow[t]{2}{*}{ No. } & \multicolumn{2}{|c|}{$\begin{array}{l}\text { Duration of } \\
\text { disease (yr) }\end{array}$} & \multirow[t]{2}{*}{$\begin{array}{l}\text { Inhibition } \\
\text { of Clq }\end{array}$} & \multirow[t]{2}{*}{$\begin{array}{l}\text { Inhibition } \\
\text { of } R F\end{array}$} & \multicolumn{2}{|c|}{$\begin{array}{l}\text { Inhibition } \\
\text { of both } \\
\text { Clq and } R F\end{array}$} \\
\hline & & Mean & (range) & & & (No.) & $(\%)$ \\
\hline $\begin{array}{lr}\text { Untreated primary disease } & \text { (I) } \\
\text { Medically treated primary disease } & \text { (II) } \\
\text { Operated without recurrence } & \text { (III) } \\
\text { Untreated recurrence } & \text { (IV) } \\
\text { Medically treated recurrence } & \text { (V) } \\
\text { All groups } \\
\text { Blood donors }\end{array}$ & $\begin{array}{r}9 \\
10 \\
11 \\
13 \\
16 \\
59 \\
100\end{array}$ & $\begin{array}{r}2 \\
5 \\
11 \\
12 \\
13 \\
10\end{array}$ & $\begin{array}{l}(0-16) \\
(0-16) \\
(1-36) \\
(5-25) \\
(3-24) \\
(0-36)\end{array}$ & $\begin{array}{r}6 \\
5 \\
4 \\
11 \\
11 \\
37 \\
22\end{array}$ & $\begin{array}{r}6 \\
4 \\
4 \\
12 \\
10 \\
36 \\
14\end{array}$ & $\begin{array}{r}6 \\
4 \\
4 \\
11 \\
10 \\
35 \\
14\end{array}$ & $\begin{array}{l}67 \\
40 \\
36 \\
85 \\
63 \\
59 \\
14\end{array}$ \\
\hline
\end{tabular}


complexes at first analysis in the five groups of patients. The mean duration of disease was longer in groups III, IV, and V than in groups I and II. Two sera of group I had a spontaneous agglutinating activity toward the IgG-coated particles, probably due to endogenous rheumatoid factor. The lowest incidence of immune complexes $(36 \%)$ was found in the group of resected patients showing no signs of relapse (group III). However, this incidence did not differ significantly from that of all other groups ( $P<$ $0 \cdot 10$, chi square test with Yates' correction).

The titre of immune complexes varied from $1 / 1$ to $1 / 131,072$ with the CIq method and from $1 / 1$ to $1 / 64$ with the RF method (Fig. 1). In group III, the titres did not exceed $1 / 8$ with either methods. In seven patients-three in group I, three in group II, one in group V-with extensive lesions of colitis, immune complexes were found in five and endogenous rheumatoid factor in one. The titres of immune complexes were respectively $1 / 32,1 / 512,1 / 8,1 / 512$, $1 / 4$ with CIq and $1 / 4,1 / 64,1 / 4,1 / 32,1 / 1$ with rheumatoid factor. The two patients with erythema nodosum had titres of $1 / 32$ and $1 / 4$ with the CIq method and of $1 / 4$ and $1 / 4$ with the RF method.

A significant correlation $(P<0.001)$ was found between the logarithms of the titres obtained with CIq and RF (Fig. 2).

Of the 100 samples from healthy blood donors, 22 reacted with CIq and 14 of these also with RF. The maximum titre with either method was, however, only $1 / 2$.

\section{CORRELATION WITH INFLAMMATORY}

PARAMETERS

The concentrations of alpha-1-antitrypsin, orosomucoid, and IgA, expressed in \% of pooled blood

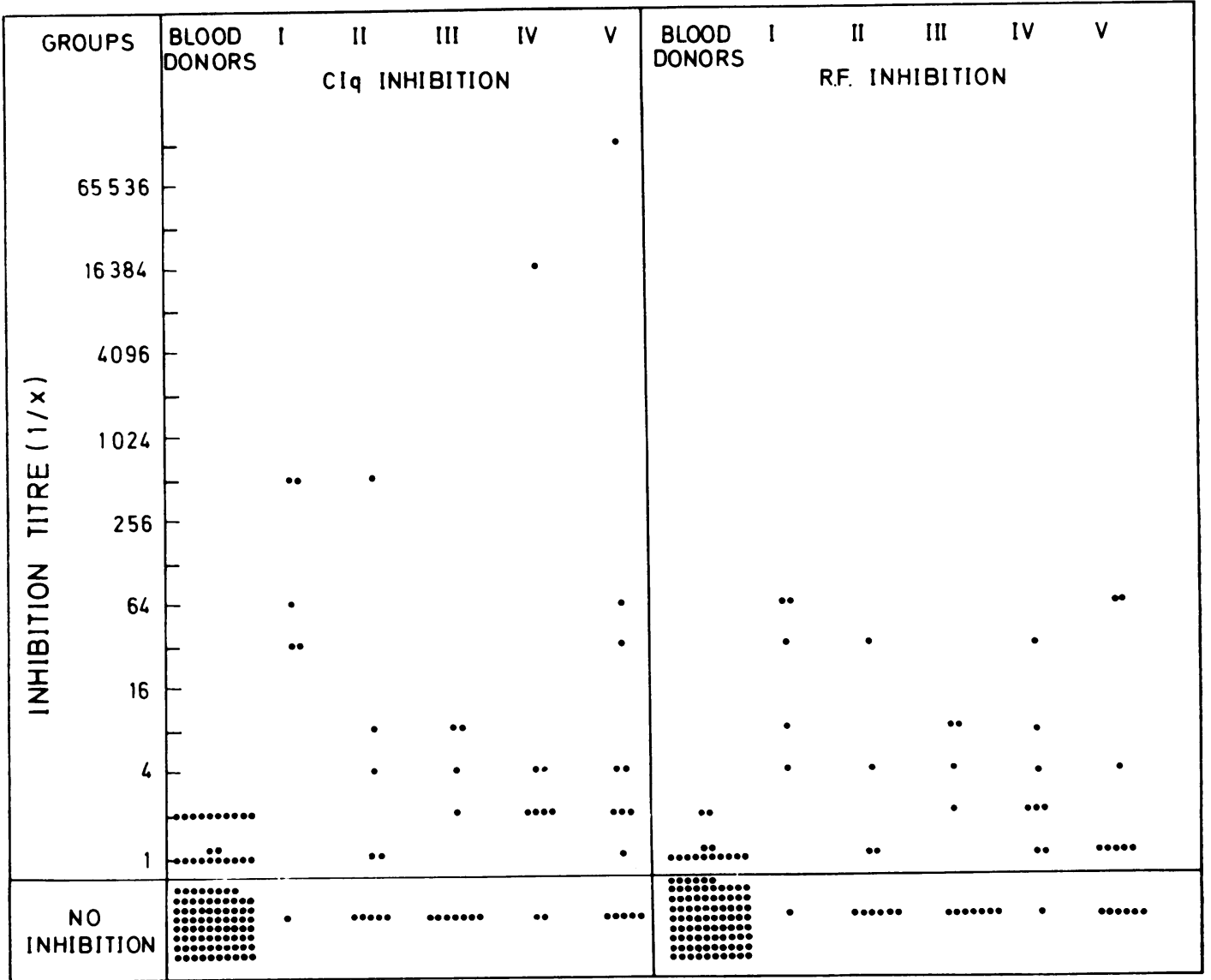

Fig. 1 Determinations of immune complexes in patients with Crohn's disease and in a control group consisting of blood donors. Group I: untreated primary disease; group II: medically treated primary disease; group III: operated without recurrence; group IV: untreated recurrence; group $V$ : medically treated recurrence. 


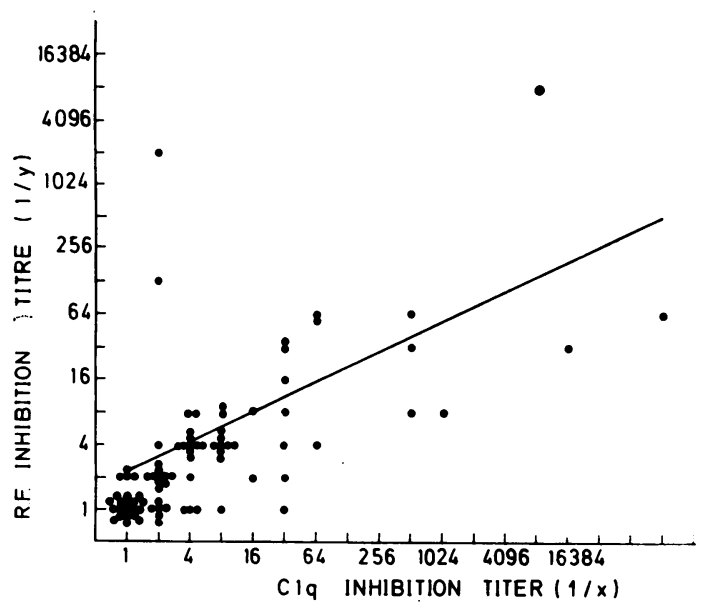

Fig. 2 Correlation between the results obtained with the CIq and the RF inhibition tests. Slope $=0.46 ;$ P for $B \neq$ $0<0.001$.

donor sera, were clearly higher, and that of iron level lower in those sera showing a significant ( $>1 / 1)$ inhibitory activity towards CIq (Table 2). This correlation between some inflammatory parameters and immune complexes was confirmed by the rheumatoid factor test; for alpha-1-antitrypsin, the statistical significance was $P<0.001$, for orosomucoid $P<0.05$, and for serum iron $P<0.005$; no correlation was found with the levels of $\operatorname{IgA}$.

\section{MEDICAL TREATMENT}

Untreated patients of group I (primary disease) and group IV (relapse) had significantly higher inhibition titres towards rheumatoid factor than did medically treated patients (groups II and V) (P $<0.01$, chi square test with Yates' correction). Inhibition titres towards CIq were not significantly higher $(P<0.01$, chi square test with Yates' correction).
In eight patients, immune complexes were determined at different stages of medical treatment (sulphasalazine in five, and prednisolone plus sulphasalazine in three). In four patients (three on prednisolone, one on sulphasalazine), the decrease of the inhibition titres closely followed the clinical improvement, and ran parallel to the normalisation of the other biological tests, as illustrated by the case shown in Fig. 3.

\section{SURGICAL TREATMENT}

Repeat determinations of immune complexes by both methods were performed on serum samples from 11 patients who were resected and who received no medical treatment after operation (Fig. 4). Four patients were tested before and after operation. In most patients, immune complexes disappeared or were undetectable more than two months after operation, except in two patients who relapsed (patients D.A. and S.R.). By $x$-ray examination, clinically asymptomatic recurrent lesions were detected in patient D.A. 12 months after operation. Radiologically detectable lesions were also found after six months in patient D.V., who had an inflammatory reaction but no detectable IC. Figure 5 illustrates the case of patient S.R.

\section{Discussion}

Our study reveals a high incidence of immune complexes in Crohn's disease, reaching $85 \%$ with the CIq-inhibition test. The IC nature of the inhibitory factors was supported by their reaction in most cases with both rheumatoid factor and CIq. The tests which are based only on CIq as applied to Crohn's disease by Mowbray et al. (1973) and by Doe et al. (1973) are liable to give false positive results because of the interaction of CIq with single stranded DNA (Agnello et al., 1970) or bacterial products (Sobel et

Table 2 Inflammatory parameters and IC titres (CIq method)

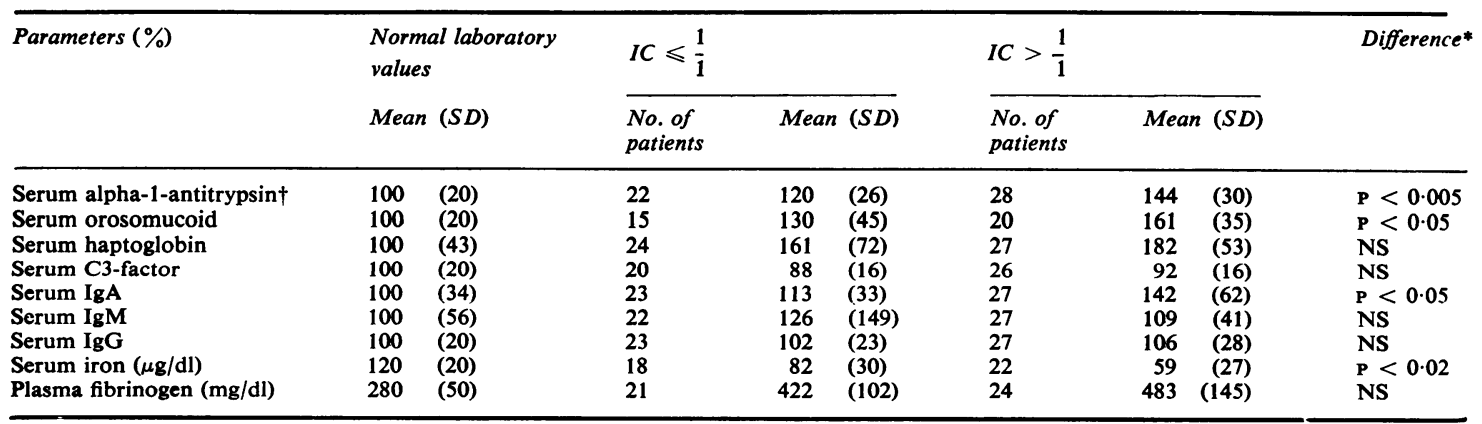

*Student's $t$ test for difference between means.

tOne patient with heterozygous alpha-1-antitrypsin was excluded.

The concentrations of serum proteins were expressed in percentages of normal values with reference to a pool of 1000 blood donor sera. 


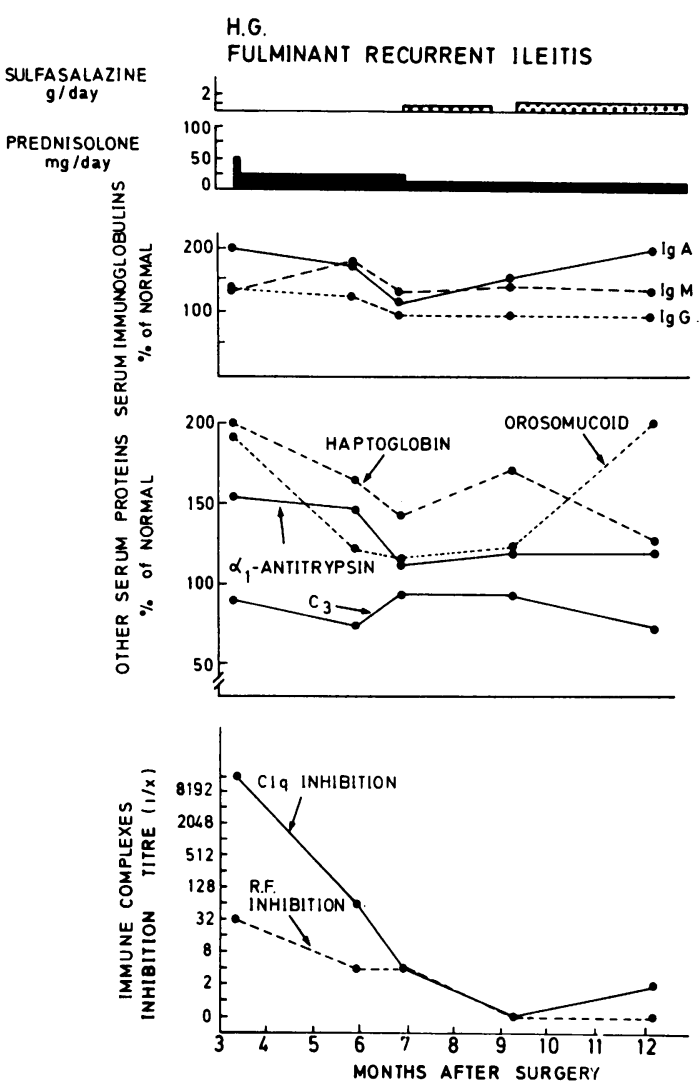

Fig. 3 Biochemical changes in a 27 year old man who had total coloproctectomy followed 10 years later by ileal resection. Three months after the second operation, he relapsed with numerous ileal ulcerations. After a dramatic clinical improvement obtained with medical treatment, the level of orosomucoid rose again, the C3-factor decreased, and a slight inhibitory activity towards CIq became detectable. However, he remained asymptomatic.

al., 1975). In our work, CIq usually gave higher titres than did rheumatoid factor. However, a clear correlation was observed between the results obtained with these two reagents. In a few cases, a wide discrepancy was observed between the inhibitory activities towards RF and CIq. This is not surprising as it is known that the specificities of these two agglutinators are quite different with respect to the size of complexes as well as the class and subclass of the antibody involved. As most inhibitory factors reacted with both RF and CIq, it can be assumed that IgG was the antibody generally present on the complexes, as IgA reacts poorly with CIq and IgM poorly with RF (Lurhuma et al., 1976).

A spontaneous agglutinating activity corresponding to endogenous rheumatoid factor was detected in two patients. This may be taken as evidence of the

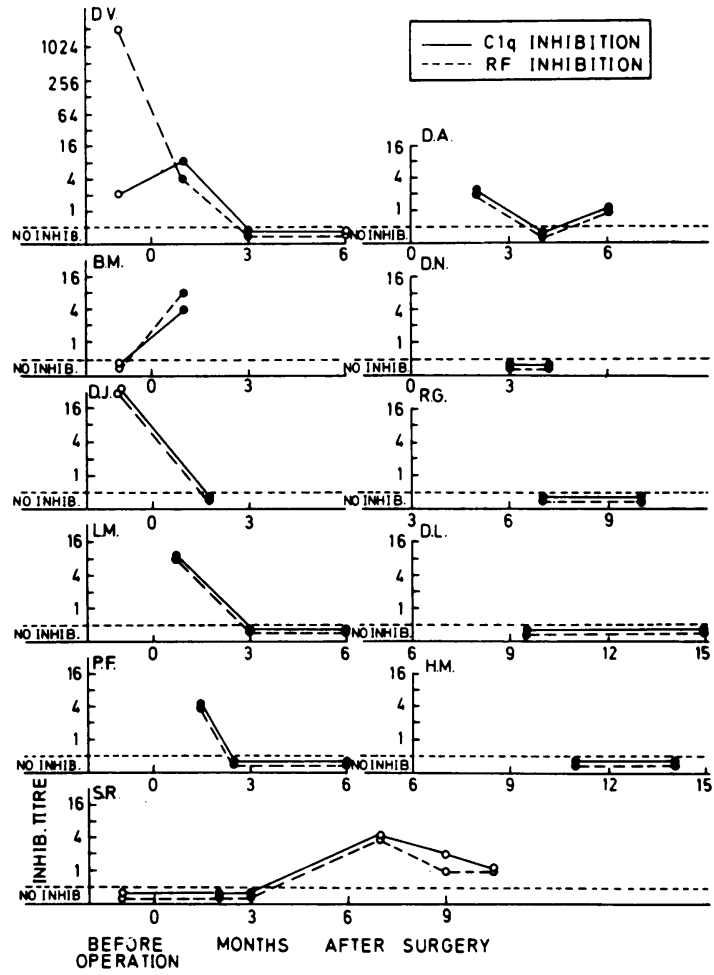

Fig. 4 Repeat determinations of immune complexes in 11 medically untreated patients at various time intervals after intestinal resection. $\bigcirc$ : stage of primary disease or relapse confirmed by $X$-rays; 0 : remission.

presence of immune complexes as it has been shown that, after inactivation of the endogenous RF, a clear inhibitory activity towards CIq is detectable (Lurhuma et al., 1976).

We have shown that the level of immune complexes correlates well with the disease activity, assessed by several inflammatory parameters. This was also demonstrated by comparing the five groups of patients. When they were clinically and biologically improved by medical or surgical treatment, a significant drop of the level of the IC was observed. In general, the IC disappeared completely three months after the intestinal resection, whereas under medical treatment the inhibition titres decreased but a slight inhibitory activity often remained.

Most of the patients with active disease had ileal lesions. Seven had extensive and predominant colonic lesions and five of them had high IC titres that, in two, reached 1/512 with CIq; however, because of the small numbers, a statistical comparison with ileal disease patients was not possible.

The activity of the disease was well reflected by the 


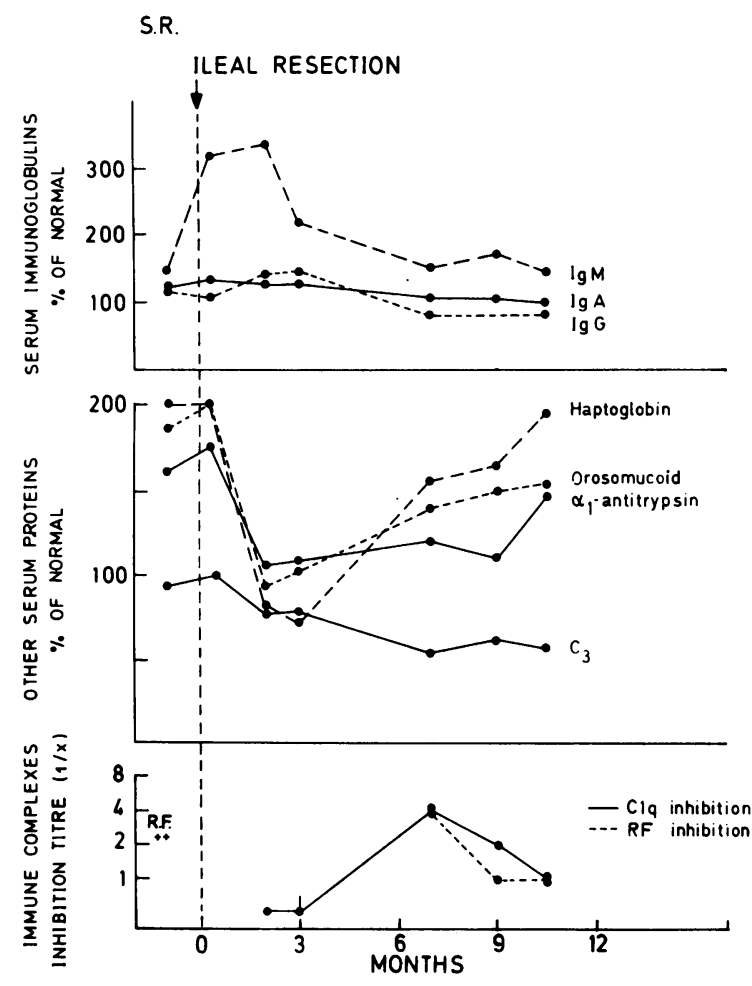

Fig. 5 Biochemical changes in a 34 year old man who underwent an ileocolic resection for Crohn's disease complicated by cutaneous fistula. Before operation his serum agglutinated Latex spontaneously (endogenous rheumatoid factor) and showed a protein profile typical of inflammation. After operation, the inflammatory reaction disappeared but, as reported for other patients

(Gelernt et al., 1972), the IgM level increased. No immune complexes were detected at two and three months after operation and he was asymptomatic. After seven months, the patient relapsed, as confirmed by the occurrence of an anal abcess easily cured by drainage and a positive $x$-ray examination later.

serum concentrations of iron, orosomucoid, alpha-1antitrypsin, and IgA. Other acute phase reactants, such as haptoglobin and the C3-factor of complement, were poor indices of the inflammatory state. In fact, both proteins are affected by the presence of circulating immune complexes. The latter can activate complement, which results in a decrease of $\mathrm{C} 3$, and also causes lysis of some erythrocytes by the 'innocent bystander' mechanism (Müller-Eberhardt, 1968) with, as a direct consequence, a decrease of haptoglobin. This consumption of $\mathrm{C} 3$ and haptoglobin opposing the increase brought about by inflammation explains why they cannot be useful indices of Crohn's disease activity.

In two patients, D.A. and S.R. (Fig. 4 and Fig. 5), the IC reappeared before the development of a clear inflammatory reaction. This suggests that the determination of immune complexes could be a better parameter for monitoring the evolution of patients with Crohn's disease than the classical inflammation parameters or the 'Crohn's disease activity index' (Best et al., 1976), which relies mainly on clinical features. The occurrence of immune complexes before the inflammatory reaction could be related to their pathogenic role or to the fact that they contain an antigen of the infectious agent responsible for the disease (Mitchell and Rees, 1970; Cave et al., 1973; Gitnick et al., 1976; Gitnick and Rosen, 1976; Whorwell et al., 1977).

Immune complexes could trigger inflammatory reactions in the gut by deposition into its tissues, as they are presumably responsible for the extraintestinal manifestations of the disease-for example, arthritis, uveitis, and erythema nodosum. However, our work provides no definite evidence for a pathogenic role of IC, nor do we know whether the antigen of the IC of Crohn's disease is really exogenous or is an autoantigen.

This work was supported by grant No. 3.4544 .76 of the Fonds de la Recherche Scientifique Médicals and a grant from the Cancer Research Fund of the Caisse Générale d'Epargne et de Retraite, Bruxelles. A.Z.L. is a fellow of the Université Nationale du Zaïre.

\section{References}

Agnello, V., Winchester R. J., and Kunkel H. G. (1970). Precipitin reactions of the CIq component of complement with aggregated $\gamma$-globulin and immune complexes in gel diffusion. Immunology, 19, 909-919.

Best, W. R., Becktel, J. M., Singleton, J. W., and Kern, F. (1976). Development of a Crohn's disease activity index. Gastroenterology, 70, 439-444.

Cave, D. R., Mitchell, D. N., Kane, S. P., and Brooke, B. N. (1973). Further animal evidence of a transmissible agent in Crohn's disease. Lancet, 2, 1120-1124.

Doe, W. F., Booth, C. C., and Brown, D. L. (1973). Evidence for complement-binding immune complexes in adult coeliac disease, Crohn's disease, and ulcerative colitis. Lancet, 1, 402-403.

Gelernt, I. M., Present, D. H. and Janowitz, H. D. (1972). Alterations in serum immunoglobulins after resection for ulcerative and granulomatous disease of the intestine. Gut, 13, 21-23.

Gitnick, G. L., Arthur, M. H., and Shibata, I. (1976). Cultivation of viral agents from Crohn's disease. Lancet, 2 , 215-217.

Gitnick, G. L., and Rosen, V. J. (1976). Electron microscopic studies of viral agents in Crohn's disease. Lancet, 2, 217219.

Jewell, D. P., and MacLennan, I. C. M. (1973). Circulating immune complexes in inflammatory bowel disease. Clinical and Experimental Immunology, 14, 219-226.

Lurhuma, A. Z., Cambiaso, C. L., Masson, P. L., and 
Heremans, J. F. (1976). Detection of circulating antigenantibody complexes by their inhibitory effect on the agglutination of Ig-G coated particles by rheumatoid factor or CIq. Clinical and Experimental Immunology, 25, 212-226.

Mitchell, D. N., and Rees, R. J. W. (1970). Agent transmissible from Crohn's disease tissue. Lancet, 2, 168-171.

Mowbray, J. F., Hoffbrand, A. V., Holborow, E. J., Seah, P. P., and Fry, L. (1973). Circulating immune complexes in dermatitis herpetiformis. Lancet, 1, 400-402.

Müller-Eberhard, H. J. (1968). Chemistry and reaction mechanisms of complement. Advances in immunology, 8, $1-80$.

Sobel, A. T., Bokisch, V. A., and Müller-Eberhard, H. J.
(1975). CIq deviation test for the detection of immune complexes, aggregates of $\mathrm{IgG}$, and bacterial products in human serum. Journal of Experimental Medicine, 142, 139150.

Whorwell, P. J., Beeken, W. L., Phillips, C. A., Little, P. K., and Roessner, K. D. (1977). Isolation of reovirus-like agents from patients with Crohn's disease. Lancet, 1, 1169. 1171.

Yonemasu, K., and Stroud, R. M. (1971). CIq: rapid purification method for preparation of monospecific antisera and for biochemical studies. Journal of Immunology, 106, 304-313. 